\title{
Aberrant expression of CD30 in neoplastic mast cells in high-grade mastocytosis
}

\author{
Karl Sotlar ${ }^{1}$, Sabine Cerny-Reiterer ${ }^{2}$, Karina Petat-Dutter ${ }^{1}$, Harald Hessel ${ }^{1}$, \\ Sabina Berezowska ${ }^{1}$, Leonhard Müllauer ${ }^{3}$, Peter Valent ${ }^{2,4}$ and Hans-Peter Horny ${ }^{5}$ \\ ${ }^{1}$ Institute of Pathology, University of Munich, Munich, Germany; ${ }^{2}$ Division of Hematology and \\ Hemostaseology, Department of Internal Medicine I, Vienna, Austria; ${ }^{3}$ Institute of Pathology, Medical \\ University of Vienna, Vienna, Austria; ${ }^{4}$ Ludwig-Boltzmann Cluster Oncology, Vienna, Austria and \\ ${ }^{5}$ Institute of Pathology of Ansbach, Ansbach, Germany
}

\begin{abstract}
Systemic mastocytosis either presents as aggressive neoplasm with short survival time or indolent systemic mastocytosis with normal life expectancy. In both instances, neoplastic mast cells usually harbor the D816Vmutated variant of KIT. Phenotypically, mast cells in systemic mastocytosis usually express CD25. However, no robust marker that discriminates between aggressive and indolent variants of systemic mastocytosis has been identified yet. We here report that $\mathrm{CD} 30$, also known as $\mathrm{Ki}-1$ antigen, is expressed in neoplastic mast cells in a majority of patients with advanced systemic mastocytosis $(11 / 13,85 \%)$, whereas in most patients with indolent systemic mastocytosis $(12 / 45,27 \% ; P<0.001)$, only a few if any mast cells stained positive for CD30. These results could be confirmed by TissueFAXS analysis in subsets of patients with indolent systemic mastocytosis $(n=7)$ and advanced systemic mastocytosis $(n=4 ; P=0.008)$. The mast cell leukemia cell line HMC-1, derived from a patient with aggressive systemic mastocytosis also expressed the CD30 protein. In addition, we were able to detect CD30 mRNA in HMC-1 cells as well as in bone marrow biopsy samples in patients with systemic mastocytosis. In contrast, CD30 transcripts could not be detected in bone marrow biopsies in cases of reactive mast cell hyperplasia and in various other myeloid neoplasms. In conclusion, CD30 is preferentially expressed in neoplastic mast cells in advanced mast cell neoplasms. Upregulated expression of CD30 in advanced systemic mastocytosis may thus be employed as a potential marker for grading systemic mastocytosis in hematopathology.
\end{abstract}

Modern Pathology (2011) 24, 585-595; doi:10.1038/modpathol.2010.224; published online 24 December 2010

Keywords: CD30; grading; immunohistochemistry; mast cell leukemia; RT-PCR; systemic mastocytosis

Systemic mastocytosis is a myeloid neoplasm characterized by abnormal growth and accumulation of neoplastic mast cells in one or more organ systems. ${ }^{1-3}$ Indolent and aggressive variants of systemic mastocytosis occur. ${ }^{4,5}$

So-called B and C findings have been defined to sub-classify systemic mastocytosis. ${ }^{4}$ The latter include organopathies especially of bone marrow, liver, and bone because of mast cell infiltration and is indicative of aggressive systemic mastocytosis. The former include a high mast cell burden $(>20 \%$ mast cells in the bone marrow; serum tryptase

Correspondence: Professor K Sotlar, MD, Institute of Pathology, Ludwig Maximilians University of Munich, Thalkirchner Straße 36, D-80337 Munich, Germany.

E-mail: Karl.Sotlar@med.uni-muenchen.de

Received 21 April 2010; revised 22 September 2010; accepted 12

October 2010; published online 24 December 2010
$>200 \mathrm{ng} / \mathrm{ml}$; organomegaly) and signs of a spread of the disease into myeloid lineages (dysmyelopoiesis; KIT ${ }^{D 816 V}$ in other myeloid lineages). In the presence of two B findings, a smouldering systemic mastocytosis is diagnosed. The absence of B and C findings usually indicates an indolent course. Mast cell leukemia, per definition, is diagnosed when neoplastic mast cells exceed $20 \%$ of nucleated cells in the bone marrow smear and/or $10 \%$ of nucleated cells in the peripheral blood. ${ }^{6,7}$ Patients with indolent systemic mastocytosis are either asymptomatic or suffer from skin lesions, mediator-related symptoms, or osteoporosis. Indolent systemic mastocytosis patients with a silent clinical course have a normal or near-normal life expectancy. ${ }^{1-3,5,8-10}$ In contrast, patients with aggressive systemic mastocytosis or mast cell leukemia have a less favorable prognosis and show a poor response to conventional cytostatic drugs. ${ }^{5,8,11}$ These patients are therefore 
candidates for experimental therapy ${ }^{11-14}$ and several attempts have been made to identify novel therapeutic targets in neoplastic mast cells..$^{5,8,12-14}$

In most patients with systemic mastocytosis, including both those with aggressive systemic mastocytosis/mast cell leukemia and those with indolent systemic mastocytosis, the transforming KIT mutation D816V can be detected. ${ }^{5,8,15-20}$ This mutation is associated with autonomous activation of the KIT receptor and is therefore considered to contribute to abnormal growth and survival of neoplastic mast cells in systemic mastocytosis. ${ }^{21}$ As $K I T^{D 816 V}$ is detectable not only in aggressive systemic mastocytosis and mast cell leukemia but also in indolent systemic mastocytosis, ${ }^{15,19,20}$ it is thought that additional pro-oncogenic pathways and markers trigger and are indicative of the aggressive disease variants, that is, aggressive systemic mastocytosis and mast cell leukemia. Unfortunately, such additional molecular markers and pathways have not yet been identified.

An important diagnostic approach in systemic mastocytosis is the immunophenotyping of neoplastic mast cells by flow cytometry and/or immunohistochemistry. ${ }^{22-24}$ In contrast to other myeloid cells, mast cells co-express tryptase and KIT and can thus be detected easily in bone marrow sections by immunostaining. ${ }^{22,25} \mathrm{~A}$ key marker of mast cells in systemic mastocytosis is CD25 (Escribano et $\mathrm{al}^{22}$; Sotlar et $\mathrm{al}^{24}$ ), which is expressed by neoplastic mast cells in almost all patients with systemic mastocytosis, whereas normal and reactive mast cells in non-mastocytic hematopoietic and non-hematopoietic disorders are usually CD25-negative. ${ }^{24}$ The expression of CD25 has also been proposed as a minor diagnostic criterion for systemic mastocytosis. ${ }^{6}$ However, CD25 expression in systemic mastocytosis is independent of the aggressiveness of the neoplasm and is thus not related to the systemic mastocytosis subtype. A number of other mast cell markers, such as CD9, CD63, CD68, and pSTAT5, are also expressed on and/or in neoplastic mast cells independent of the disease variant. ${ }^{26,27}$ Some of these markers may be expressed by mast cells at slightly higher or lower levels in aggressive systemic mastocytosis or mast cell leukemia compared with indolent systemic mastocytosis. ${ }^{28}$ However, so far no robust immunological marker that would discriminate between the indolent and aggressive variants of systemic mastocytosis has been identified. The CD30 antigen, also known as Ki-1 antigen, is a member of the tumor necrosis factor receptor superfamily. ${ }^{29,30}$ A number of studies have shown that CD30 is expressed by neoplastic cells in a small and distinct spectrum of human neoplasms, including embryonal carcinoma, Hodgkin lymphoma, anaplastic large cell lymphoma, and in rare cases of extramedullary myeloid sarcoma. ${ }^{30-32}$ In addition, CD30 may be expressed in activated lymphoid cells in the course of viral infection, for example, infectious mononucleosis. ${ }^{33}$ With the exception of single cases of myeloid sarcoma, CD30 expression has not been reported in the context of myeloid neoplasms so far. We here report that CD30 is expressed by neoplastic mast cells in certain patients with systemic mastocytosis. CD30 expression was found to correlate with the subtype of systemic mastocytosis in that in most patients with high-grade systemic mastocytosis (aggressive systemic mastocytosis or mast cell leukemia) the majority of mast cells were CD30-positive, whereas in most patients with indolent systemic mastocytosis, the great majority of mast cells were found to be CD30-negative.

\section{Patients and methods}

\section{Patients and Diagnoses}

Immunohistochemical evaluation of CD30 expression in tryptase-positive mast cells was performed on bone marrow biopsies from a total of 61 patients with mastocytosis (45 patients with typical indolent systemic mastocytosis, 2 with smouldering systemic mastocytosis, 5 with aggressive systemic mastocytosis, 6 with mast cell leukemia, 3 with cutaneous mastocytosis) and 1 patient with monoclonal mast cell activation syndrome. Serum tryptase levels were available for about half of these patients (indolent systemic mastocytosis, $n=26$; smouldering systemic mastocytosis, $n=2$; aggressive systemic mastocytosis, $n=2$; mast cell leukemia, $n=2$, cutaneous mastocytosis, $n=3$; monoclonal mast cell activation syndrome, $n=1$; Table 1 ). The control group consisted of 15 patients with bone marrow mast cell hyperplasia, 15 with various myelogenous neoplasms other than systemic mastocytosis (chronic myeloid leukemia, $n=2$; primary myelofibrosis, $n=4$; polycytemia vera, $n=1$; myelodysplastic syndrome, $n=4$; chronic myelomonocytic leukemia, $n=1$; acute myeloid leukemia, $n=3$ ), 3 with Hodgkin lymphoma ( 2 patients with nodal involvement and 1 patient with medullary involvement), and 3 with testicular germ cell tumors ( 2 with embryonal carcinoma, 1 with seminoma).

Molecular analysis for the assessment of CD30 mRNA expression was performed in 9 patients with systemic mastocytosis (indolent systemic mastocytosis, $n=5$; aggressive systemic mastocytosis, $n=3$; mast cell leukemia, $n=1$ ) and 13 patients without mastocytosis, 3 of which showed a marked increase in bone marrow mast cells. The latter included two patients with an unclassifiable myeloproliferative neoplasm with eosinophilia and one patient with a tumor-free bone marrow in Hodgkin lymphoma. Unfortunately, no results of molecular analyses regarding aberrations in PDGFRA, PDGFRB, or FGFR1 genes were available in the patients with the unclassifiable myeloproliferative neoplasms with eosinophilia. The remaining cases consisted of one patient with a myelodysplastic syndrome, two with plasma cell myeloma, one with medullary 
Table 1 Summary of patient characteristics, immunohistochemical, serological, and molecular biological findings

\begin{tabular}{|c|c|c|c|c|c|c|c|}
\hline Pat. & Age & Gender & Diagnosis & Tr+cells (\%) & $S T(\mathrm{ng} / \mathrm{ml})$ & $K I T^{D 816 V}$ & СDЗо IHC \\
\hline 1 & 39 & $\mathrm{~F}$ & MMAS & $<5$ & 11.9 & - & - \\
\hline 2 & 46 & $\mathrm{~F}$ & $\mathrm{CM}$ & $<5$ & 7.8 & - & - \\
\hline 3 & 42 & M & $\mathrm{CM}$ & $<5$ & 14.2 & + & - \\
\hline 4 & 37 & $\mathrm{~F}$ & $\mathrm{CM}$ & $<5$ & 16.9 & ND & - \\
\hline 5 & 49 & M & ISM & $<5$ & 17.1 & + & ++ \\
\hline 6 & 43 & M & ISM & $<5$ & 20.0 & - & + \\
\hline 7 & 39 & M & ISM & $<5$ & 22.7 & + & - \\
\hline 8 & 50 & M & ISM & $<5$ & 27.6 & - & - \\
\hline 9 & 59 & $\mathrm{~F}$ & ISM & $<5$ & 49.6 & - & - \\
\hline $10^{\mathrm{a}}$ & 30 & M & ISM & 5 & 11.3 & - & - \\
\hline 11 & 40 & M & ISM & 5 & 15.8 & + & - \\
\hline 12 & 37 & $\mathrm{~F}$ & ISM & 5 & 23.3 & + & - \\
\hline 13 & 42 & M & ISM & 5 & 24.8 & + & - \\
\hline $14^{\mathrm{a}}$ & 60 & M & ISM & 5 & 42.2 & - & - \\
\hline $15^{\mathrm{a}}$ & 54 & M & ISM & 5 & 60.1 & + & - \\
\hline 16 & 52 & M & ISM & $5-10$ & 16.5 & + & - \\
\hline 17 & 38 & M & ISM & $5-10$ & 26.7 & + & - \\
\hline $18^{\mathrm{a}}$ & 48 & M & ISM & 10 & 11.1 & + & - \\
\hline 19 & 41 & M & ISM & 10 & 14.5 & - & + \\
\hline $20^{\mathrm{a}}$ & 33 & M & ISM & 10 & 36.0 & + & - \\
\hline 21 & 46 & $\mathrm{~F}$ & ISM & 10 & 790.0 & + & - \\
\hline 22 & 44 & M & ISM & 15 & 69.4 & + & + \\
\hline 23 & 50 & M & ISM & 15 & 169.0 & + & + \\
\hline 24 & 52 & M & ISM & 15 & 229.0 & + & + \\
\hline $25^{\mathrm{a}}$ & 51 & M & ISM & 20 & 53.2 & + & + \\
\hline 26 & 54 & M & ISM & 20 & 250.0 & + & + \\
\hline 27 & 44 & $\mathrm{~F}$ & ISM & 30 & 17.5 & + & - \\
\hline $28^{\mathrm{a}}$ & 30 & M & ISM & 30 & 122.0 & + & - \\
\hline 29 & 60 & $\mathrm{~F}$ & ISM & 30 & 188.0 & + & - \\
\hline 30 & 61 & M & ISM & 40 & 650.0 & ND & ++ \\
\hline 31 & 48 & M & ISM & 1 & NA & + & - \\
\hline 32 & 36 & $\mathrm{~F}$ & ISM & 1 & NA & + & - \\
\hline 33 & 32 & $\mathrm{~F}$ & ISM & 1 & NA & + & - \\
\hline 34 & 29 & M & ISM & 3 & NA & + & - \\
\hline 35 & 22 & $\mathrm{~F}$ & ISM & 3 & NA & + & - \\
\hline $36^{\mathrm{b}}$ & 43 & $\mathrm{~F}$ & ISM & 3 & NA & + & + \\
\hline 37 & 44 & $\mathrm{M}$ & ISM & 3 & NA & + & - \\
\hline 38 & 44 & $\mathrm{M}$ & ISM & 5 & NA & + & - \\
\hline 39 & 42 & $\mathrm{~F}$ & ISM & 5 & NA & + & - \\
\hline $40^{\mathrm{b}}$ & 48 & $\mathrm{M}$ & ISM & 5 & NA & + & + \\
\hline $41^{\mathrm{b}}$ & 52 & $\mathrm{~F}$ & ISM & 5 & NA & + & - \\
\hline 42 & 45 & $\mathrm{~F}$ & ISM & 5 & NA & + & - \\
\hline $43^{\mathrm{b}}$ & 29 & $\mathrm{~F}$ & ISM & 5 & NA & + & + \\
\hline 44 & 52 & $\mathrm{~F}$ & ISM & $5-10$ & NA & + & - \\
\hline 45 & 57 & $\mathrm{~F}$ & ISM & $5-10$ & NA & + & - \\
\hline 46 & 28 & $\mathrm{M}$ & ISM & 10 & NA & + & ++ \\
\hline 47 & 37 & $\mathrm{~F}$ & ISM & 10 & NA & + & - \\
\hline 48 & 54 & $\mathrm{~F}$ & ISM & $10-15$ & NA & + & - \\
\hline $49^{\mathrm{b}}$ & 77 & $\mathrm{~F}$ & ISM & $15-20$ & NA & + & - \\
\hline $50^{\mathrm{a}}$ & 42 & M & SSM & 35 & 650.0 & + & ++ \\
\hline $51^{\mathrm{a}}$ & 47 & $\mathrm{~F}$ & SSM & 65 & 104.0 & + & + \\
\hline $52^{\mathrm{b}}$ & 59 & M & ASM & 50 & NA & + & ++ \\
\hline $53^{\mathrm{b}}$ & 68 & $\mathrm{~F}$ & ASM & 50 & NA & + & ++ \\
\hline $54^{\mathrm{b}}$ & 49 & $\mathrm{~F}$ & ASM & 80 & NA & + & ++ \\
\hline $55^{\mathrm{a}}$ & 22 & M & ASM & 50 & 134.0 & + & + \\
\hline $56 a^{a, c}$ & 60 & M & ASM & 50 & 212.0 & + & + \\
\hline $56 \mathrm{~b}^{\mathrm{a}, \mathrm{c}}$ & 60 & M & MCL & 90 & 393.0 & + & ++ \\
\hline 57 & 26 & M & MCL & 80 & 1910.0 & + & ++ \\
\hline 58 & 63 & M & MCL/AML & 60 & 191.0 & + & - \\
\hline $59^{\mathrm{b}}$ & 76 & M & MCL & 50 & NA & + & ++ \\
\hline 60 & 48 & M & MCL & 65 & NA & + & + \\
\hline 61 & 65 & M & MCL & 75 & NA & + & ++ \\
\hline 62 & 60 & M & MCL & 85 & NA & + & - \\
\hline
\end{tabular}

Abbreviations: AML, acute myelogenous leukemia; ASM, aggressive SM; CM, cutaneous mastocytosis; F, female; IHC, immunohistochemistry; ISM, indolent systemic mastocytosis; M, male; MMAS, monoclonal mast cell activation syndrome; NA, not applicable; SSM, smouldering SM; MCL, mast cell leukemia; ST, serum tryptase; Tr+, tryptase-positive.

${ }^{\mathrm{a}}$ These patients were analyzed by TissueFAXS.

${ }^{\mathrm{b}}$ These patients were investigated for the presence of CD30 mRNA by RT-PCR (Table 2).

${ }^{\mathrm{C}}$ The same patient was investigated at two time-points.

- , 'negative', $<10 \%$ of MC express CD30.

+ , 'positive', $10-50 \%$ of MC clearly express CD30.

++ , 'strongly positive', $>50 \%$ of MC clearly express CD30. 
Table 2 Detection of CD30 mRNA in formalin-fixed and paraffin-embedded tissues of various subtypes of mastocytosis and controls

\begin{tabular}{|c|c|c|c|c|c|c|}
\hline Pat. & Diagnosis & Tissue & $T r+$ cells & $K I T^{D 816 V}$ & CD30 IHC & CD30 mRNA \\
\hline 1 & ISM & $\mathrm{BM}$ & $3 \%$ & + & - & + \\
\hline 2 & ISM & $\mathrm{BM}$ & $5 \%$ & + & + & + \\
\hline 3 & ISM & $\mathrm{BM}$ & $5 \%$ & + & - & - \\
\hline 4 & ISM & $\mathrm{BM}$ & $5 \%$ & + & - & + \\
\hline 5 & ISM & $\mathrm{BM}$ & $15-20 \%$ & + & - & - \\
\hline 6 & ASM & $\mathrm{BM}$ & $50 \%$ & + & ++ & + \\
\hline 7 & ASM & $\mathrm{BM}$ & $50 \%$ & + & ++ & + \\
\hline 8 & ASM & $\mathrm{BM}$ & $80 \%$ & + & ++ & + \\
\hline 9 & MCL & $\mathrm{BM}$ & $50 \%$ & + & ++ & + \\
\hline 10 & MPNEo-U ${ }^{a}$ & $\mathrm{BM}$ & $>3 \%$ & - & - & - \\
\hline 11 & MPNEo-U ${ }^{\mathrm{b}}$ & $\mathrm{BM}$ & $>3 \%$ & - & - & - \\
\hline 12 & Tumor-free BM in HL & $\mathrm{BM}$ & $>3 \%$ & - & - & - \\
\hline 13 & MDS-RCMD & $\mathrm{BM}$ & $<3 \%$ & NA & - & - \\
\hline 14 & PCM & $\mathrm{BM}$ & $<3 \%$ & NA & - & - \\
\hline 15 & PCM & $\mathrm{BM}$ & $<3 \%$ & NA & - & _- \\
\hline 16 & DLBCL & $\mathrm{BM}$ & $<3 \%$ & NA & - & - \\
\hline 17 & $\mathrm{HL}$ & LN & NA & NA & + & + \\
\hline 18 & HL & LN & NA & NA & + & + \\
\hline 19 & HL & BM & NA & NA & + & + \\
\hline 20 & $\mathrm{EC}$ & Testicle & NA & NA & + & + \\
\hline 21 & EC & Testicle & NA & NA & + & + \\
\hline 22 & Seminoma & Testicle & NA & NA & - & - \\
\hline
\end{tabular}

Abbreviations: ASM, aggressive SM; AHNMD, associated clonal hematological non-mast cell disease; $\beta 2$-MG, beta-2 microglobulin; BM, bone marrow; DLBCL, diffuse large B-cell lymphoma; EC, embryonal carcinoma; HL, Hodgkin lymphoma; ISM, indolent systemic mastocytosis; LN, lymph node; MPNEo-U, unclassified myeloproliferative neoplasm with eosinophilia; NA, not analyzed; PCM, plasma cell myeloma; Tr+, tryptase-positive.

a 25 year-old male with MPNEo and CD25-positive spindle-shaped MC.

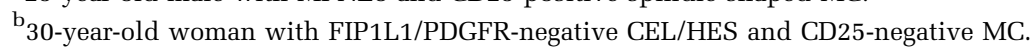

infiltrates of a diffuse large B-cell lymphoma, one with medullary infiltrates of Hodgkin lymphoma, two with nodal Hodgkin lymphoma, and three with testicular germ cell tumors (Table 2). Routinely processed bone marrow trephine biopsy specimens, lymph node biopsies, and testicular biopsies were drawn from the archives of the Institutes of Pathology, University of Vienna, Vienna, Austria; University of Munich, Munich, Germany; and Klinikum Ansbach, Ansbach, Germany. All biopsy specimens had been fixed in 5\% neutral-buffered ethanol-formaldehyde solution. In the Viennese patients, bone marrow aspirates were obtained and mononuclear cells were isolated for molecular analyses using Ficoll. Diagnoses were established according to the WHO classification..$^{6,7}$

\section{Immunohistochemistry}

Immunohistochemical investigations were performed on archival bone marrow trephine biopsies taken from the iliac crest after informed consent had been obtained from the patients. After formalinfixation, these specimens had been mildly decalcified overnight in edetic acid, and embedded in paraffin wax. Sections were cut at $3 \mu \mathrm{m}$ and stained for CD30 by the indirect immunoperoxidase-staining technique as described elsewhere. ${ }^{24}$

Diagnostic sections were stained with H\&E, Giemsa, and for naphthol AS-D chloroacetate esterase. Immunohistochemical investigations for tryptase (mAb G3, 1:500, Santa Cruz Biotechnology,
Santa Cruz, CA, USA), CD117, CD25 (Novocastra, New Castle, UK), and CD34 (QBEND10; Biocare, Walnut Creek, CA, USA) were performed with the avidin-biotin immunoperoxidase-staining technique and the Vectastain Universal ABC-AP Kit (Vector Laboratories, Burlingham, CA, USA). ${ }^{25,34}$ The anti-CD30 monoclonal antibody Ber-H2 (Dako, Glostrup, Denmark; working dilution: 1:20) was applied at room temperature overnight. The slides were then washed in tris-buffered saline, incubated in biotinylated goat anti-mouse IgG for $30 \mathrm{~min}$ at room temperature, washed in tris-buffered saline, and then exposed to biotin-peroxidase complex for 30 min. 3-Amino-9-ethylcarbazole (Sigma, St Louis, MO, USA) was employed as chromogen. All slides were counterstained in Mayer's Hemalaun and mounted in Aquatex. A semi-quantitative scoring system for CD30 was applied using the following categories: 'negative' $(-),<10 \%$ of mast cells in tryptase-positive mast cell infiltrates express immunohistochemically detectable CD30; 'positive' (+), $10-50 \%$ of mast cells clearly express CD30; 'strongly positive' $(++),>50 \%$ of mast cells clearly express CD30.

\section{Quantification of CD30 Expression by TissueFAXS}

CD30 expression in tryptase-positive mast cells of compact mast cell infiltrates was quantified objectively in serial bone marrow sections obtained from seven patients with indolent systemic mastocytosis and four patients with advanced systemic mastocy- 
tosis (two with smouldering systemic mastocytosis and two with aggressive systemic mastocytosis; one patient with aggressive systemic mastocytosis progressed to mast cell leukemia and was analyzed at two different points in time) using the TissueFAXS system (TissueGnostics, Vienna, Austria). ${ }^{35,36}$ In detail, mast cell infiltrates were identified in tryptase-stained bone marrow sections and scanned by Histo-FAXS. Expression of CD30 was examined on serial bone marrow sections using Histo-FAXS. Nucleated cells within mast cell infiltrates were defined by nuclear color and shape. The cytoplasm in these lesional cells was examined for the expression of tryptase and the co-expression of CD30 by Histo-FAXS. Both, spindle-shaped and round cells were included in the calculation. The mean intensity of antibody-staining reactions obtained was plotted against the Hemalaun mean intensity, and was expressed as percentage of all nucleated (Hemalaun-positive) cells in form of DotPlots and histograms.

\section{Analysis of KIT Codon 816 Mutations}

In 36 patients (Table 1, patients $1-30,50,51,55-58$ ), mRNA extracted from isolated bone marrow mast cells was evaluated for the presence of KIT codon 816 point mutations, especially D816V, by RT-PCR and Hinf I digestion. ${ }^{18}$ In the remaining 39 patients with mastocytosis formalin-fixed and paraffinembedded bone marrow biopsies were analyzed for the $c$-kit genotype by peptide nucleic acid-mediated PCR clamping and melting point analysis of amplification products as described previously. ${ }^{37,38}$ The human mast cell leukemia cell line HMC-1.2, which is known to display the KIT mutation D816V, served as a positive control. ${ }^{21}$ HMC-1 cells were kindly provided by Dr Butterfield of the Mayo Clinic, Rochester, MN, USA.

\section{Evaluation of CD30 mRNA Expression}

Five sections were cut at $10 \mu \mathrm{m}$ from blocks of formalin-fixed and paraffin-embedded tissues (Table 2) under RNAse-free conditions. The sections were deparaffinized and total RNA was isolated using the High Pure FFPE RNA Micro Kit (Roche Diagnostics, Mannheim, Germany). RNA quantity was measured on a NanoDrop ND-1000 spectrophotometer (Peqlab Biotechnologie, Erlangen, Germany). The isolated RNA was stored at $-80^{\circ} \mathrm{C}$ until further processing. In addition, mRNA from native HMC-1 cells was also analyzed. The 'Universal Probes Library' software was used for the design of the RT-PCR primers (https://www.roche-appliedscience.com).

Aliquots of 100-500 ng of total RNA were reverse transcribed with the M-MuLV reverse transcriptase (Roche Diagnostics) and random hexamere primers (Hexanucleotide Mix, Roche Diagnostics). In brief,
Table 3 PCR primers

\begin{tabular}{lll}
\hline Primers & Sequence $\left(5^{\prime}-3^{\prime}\right)$ & GB access \\
\hline CD30-F & CACATCAGCCACCAACTCC & NM_000417 \\
CD30-B & TGTCCTTCTCAGCCATATCCT & \\
PPP1CA-F & CCTATAAGATCAAGTACCCCGAGA & NM_002708 \\
PPP1CA-B & GATGTTGTAGCGTCTCTTGCAC & \\
\hline
\end{tabular}

Abbreviation: GB access, GenBank accession number.

RNA and primers were mixed in a total volume of $10 \mu \mathrm{l}$, denatured at $70^{\circ} \mathrm{C}$ for $5 \mathrm{~min}$, and then cooled on ice. Reverse transcription was performed by incubation at $37^{\circ} \mathrm{C}$ for $1 \mathrm{~h}$ after the addition of $5 \times$ RT buffer, dNTPs (0.5 mM each), and reverse transcriptase $(2 \mathrm{U} / \mu \mathrm{l})$ in a final volume of $20 \mu \mathrm{l}$. The enzyme was inactivated by incubation for $10 \mathrm{~min}$ at $90^{\circ} \mathrm{C}$.

Amplification of $1.5 \mu \mathrm{l}$ of template cDNA was carried out in a final volume of $15 \mu \mathrm{l}$ containing $0.2 \mu \mathrm{M}$ of each primer (Table 3) and 0.6 U AmpliTaq Gold DNA Polymerase (Applied Biosystems, USA). After initial denaturation for $5 \mathrm{~min}$ at $95^{\circ} \mathrm{C}, 50$ PCR cycles were performed with the following cycling conditions: denaturation at $95{ }^{\circ} \mathrm{C}$ for $30 \mathrm{~s}$, annealing at $56{ }^{\circ} \mathrm{C}$ for $30 \mathrm{~s}$, and elongation at $72^{\circ} \mathrm{C}$ for $30 \mathrm{~s}$. The final amplification cycle was completed by an elongation step at $72{ }^{\circ} \mathrm{C}$ for $10 \mathrm{~min}$. PCR products were analyzed by electrophoresis on $2.5 \%$ agarose gels in $1 \times$ TBE Buffer and ethidium bromide staining.

\section{Statistical Analysis}

Fisher's exact test for $2 \times 2$ contingency tables was used to test for differences in proportions on nominal variables. The Mann-Whitney $U$-test was applied to test for differences of medians of continuous variables in the analysis of TissueFAXS results between indolent systemic mastocytosis and smouldering systemic mastocytosis/aggressive systemic mastocytosis/mast cell leukemia and correlation between continuous variables (ie, CD30 vs serum tryptase) was determined with the nonparametric Spearman correlation coefficient. The significance level was set at 0.05 . Statistical analysis of the data was performed with SPSS software, version 17.0 (SPSS, Chicago, IL, USA).

\section{Results}

\section{Preferential Expression of CD30 in Advanced Subtypes of Mastocytosis}

Immunohistochemcial investigation showed CD30 to be expressed in tryptase-positive mast cells in 23/61 (38\%) patients with mastocytosis (patient 1, Table 1 was not included because of insufficient diagnostic criteria for mastocytosis). In bone marrow biopsies from patients with cutaneous mastocytosis, CD30 staining was completely 'negative' $(-)$ in all 
three cases investigated. Patients with advanced forms of the disease, that is, smouldering systemic mastocytosis, aggressive systemic mastocytosis, and mast cell leukemia, exhibited 'positive' $(+)$ or even 'strongly positive' $(++)$ expression of CD30 in most cases (11/13, 85\% ; Figure 1). Interestingly, however, in one patient with mast cell leukemia who transformed to acute myeloid leukemia, mast cells were found to display only weak expression of CD30 (patient 58) and in another patient with mast cell leukemia, CD30 expression was not detectable (patient 62). In contrast to the high-grade mastocytoses, clear-cut expression of CD30 was found in only $12 / 45(27 \%)$ of patients with indolent systemic mastocytosis, the largest group of patients in this study. In detail, nine patients displayed a 'positive' $(+)$ and three patients 'strongly positive' $(++)$ expression of CD30 in their bone marrow mast cells.

In the group of patients with systemic mastocytosis for whom both detailed bone marrow data and serum tryptase levels were available $(n=36$, patients $1-30,50,51,55-58)$, there was a weak tendency toward CD30 positivity in patients with a marked increase in bone marrow mast cells $(\geq 10 \%$ of nucleated cells; $7 / 13,54 \%$ ) as compared with those patients with low mast cell numbers $(<10 \%$ of nucleated cells; $2 / 13,15 \%$ ) which, however, did not reach statistical significance $(P=0.097)$. There was also no significant difference in CD30 expression between $K I T^{\mathrm{D} 816 \mathrm{~V}}$-positive $(21 / 52,40 \%)$ and $K T^{\mathrm{D} 816 \mathrm{~V}}$-negative indolent systemic mastocytosis cases $(2 / 6,33 \% ; P=1.0)$. However, when indolent systemic mastocytosis patients were stratified according to their serum tryptase levels $60 \%(6 / 10)$ of patients with serum tryptase levels $\geq 50 \mathrm{ng} / \mathrm{ml}$ showed 'positive' $(+)$ or 'strongly positive' $(++)$ expression of CD30 by their bone marrow mast cells compared with only 19\% (3/16) of indolent systemic mastocytosis patients with serum tryptase levels $<50 \mathrm{ng} / \mathrm{ml}(P=0.046)$. The patient with monoclonal mast cell activation syndrome did not exhibit expression of CD30 by bone marrow mast cells.
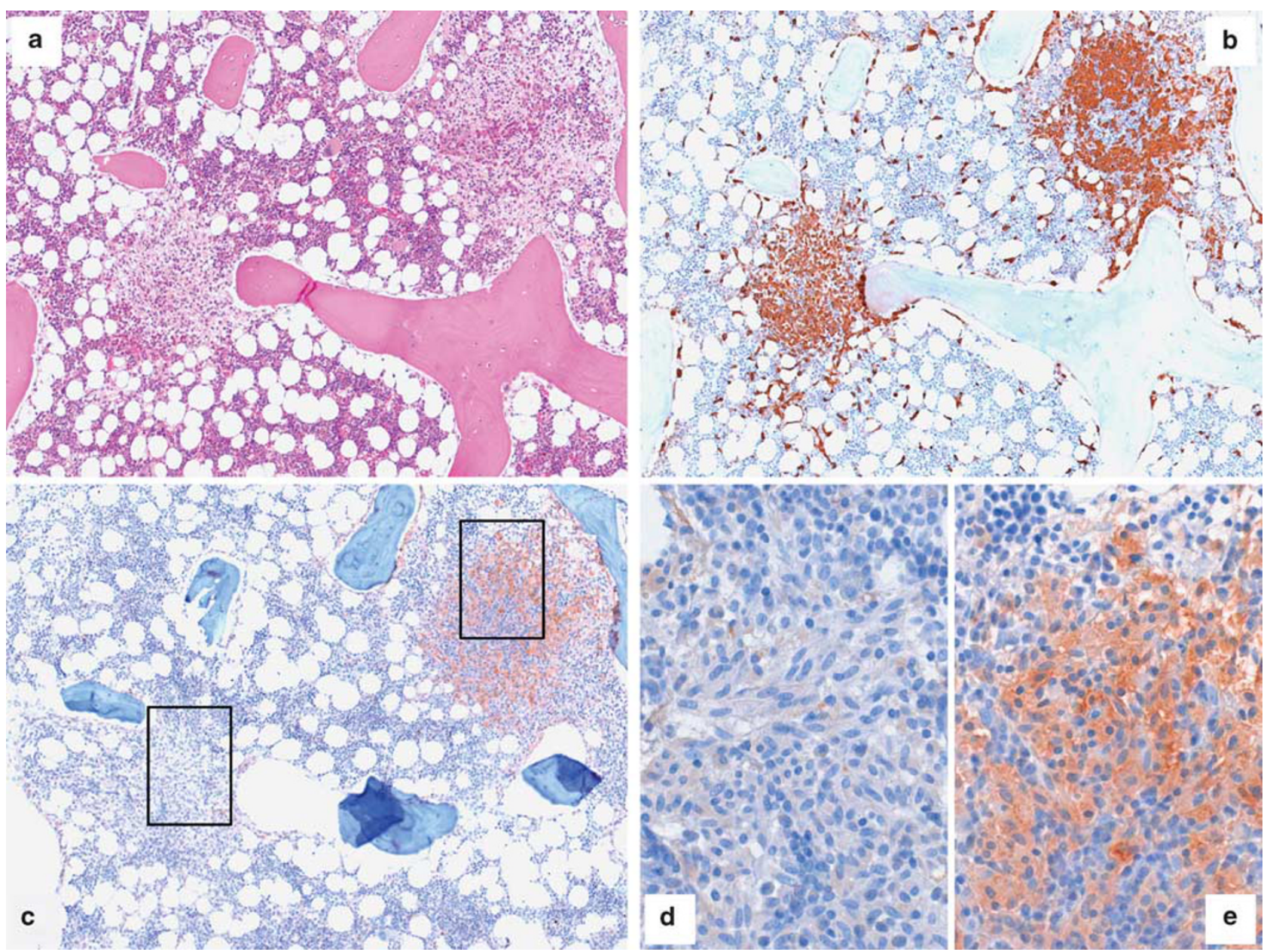

Figure 1 Inconstant expression of CD30 in indolent systemic mastocytosis. Serial bone marrow sections in a patient with indolent systemic mastocytosis stained with H\&E (a) and with antibodies against tryptase (b) and CD30 (c). Two compact mast cell infiltrates are easily visible even in the routine H\&E staining. Compact as well as diffuse mast cell infiltrates are highlightened by anti-tryptase immunohistochemistry. Interestingly, in this case mast cells of only one compact infiltrate expressed CD30. Panels (d) and (e) show higher magnifications of the anti-CD30 immunostain in (c). 
In summary, a highly significant difference $(P<0.001)$ in a clear-cut expression of CD30 in mast cells was found between patients with advanced systemic mastocytosis (11/13, 85\%), and those with the indolent form of the disease (12/45, 27\%). In addition, CD30 expression was significantly increased in patients with markedly elevated serum tryptase levels ( $\geq 50 \mathrm{ng} / \mathrm{ml} ; P=0.008$ ). In general, the high-grade mastocytoses, especially aggressive systemic mastocytosis and mast cell leukemia, presented with a stronger staining intensity for CD30 and a higher percentage of CD30-positive mast cells. In contrast, with only $3(6 \%)$ exceptional cases of indolent systemic mastocytosis showing a strong CD30 staining, the vast majority of the 45 indolent systemic mastocytosis cases investigated presented with only a minority of mast cells stained weakly or not at all (Figures 1-3).

The bone marrow mast cells in non-neoplastic conditions and various non-mastocytic myeloid neoplasms did not express immunohistochemically detectable amounts of CD30. The same was true for the seminoma investigated. As positive controls, neoplastic Hodgkin and Reed-Sternberg cells from patients with Hodgkin lymphoma and tumor cells from the two testicular embryonal carcinomas were found to strongly express CD30 (not shown).

\section{Detection of CD30 by TissueFAXS}

To confirm expression of CD30 in tryptase-positive mast cell infiltrates by a non-subjective method, TissueFAXS was applied in seven patients with indolent systemic mastocytosis and four patients with advanced systemic mastocytosis (ie, smouldering systemic mastocytosis, $n=2$; aggressive systemic mastocytosis, $n=1$; mast cell leukemia, $n=1$; see Table 1 ). The patients with aggressive systemic mastocytosis later progressed to mast cell leukemia and were analyzed at two time points. This confirmed the strong expression of CD30 in advanced systemic mastocytosis (staining intensity, mean 11.4, range 6.3-30.9), whereas in less advanced forms of systemic mastocytosis, mast cell infiltrates expressed lower levels of CD30 (staining intensity, mean 4.7, range 1.2-9; $P=0.012$; Figure 3a). A highly significant positive correlation of CD30 expression and serum tryptase levels, as described above for indolent systemic mastocytosis, became obvious also for the TissueFAXS analysis of compact mast cell infiltrates in indolent systemic mastocytosis and aggressive systemic mastocytosis/mast cell leukemia $(P=0.008 ; r=0.72$; Figure $3 b)$.

\section{Detection of CD30 Transcripts in Formalin-Fixed and Paraffin-Embedded Bone Marrow Biopsies in Mastocytosis}

RT-PCR analysis was performed to confirm CD30 mRNA expression by neoplastic mast cells. For this purpose, randomly selected bone marrow biopsies were used, including various systemic mastocytosis subtypes (Table $2, n=9$ ) and 13 patients without mastocytosis with and without CD30-positive neoplasms.

In the latter group, in line with the immunohistochemical results, no CD30 transcripts were detectable in the three patients with markedly increased bone marrow mast cells. Two of these patients had unclassifiable myeloproliferative neoplasm and eosinophilia. Of note, one of patient presented with a marked increase in CD25-positive spindle-shaped mast cells. The third patient had a Hodgkin lymphoma and showed a marked increase in bone marrow mast cells in his tumor-free bone marrow. In addition, no CD30 transcripts were detected in the four bone marrow biopsies of patients with myelodysplastic syndrome $(n=1)$, plasma cell myeloma $(n=2)$, and diffuse large B-cell lymphoma $(n=1$; Table 2). In contrast, high levels of CD30 transcripts were detected in biopsies containing Hodgkin lymphomas $(n=3)$ and embryonal carcinoma $(n=2)$, neoplasms typically displaying immunohistochemically detectable expression of CD30. The seminoma was CD30-negative by both immunohistochemistry and nested RT-PCR.

Among the patients with mastocytosis detection of CD30 mRNA was found to vary (Figure 4). Although CD30 transcripts were detected in all four patients with aggressive systemic mastocytosis (patients 6-9, Table 2), they were found in only three of five patients with indolent systemic mastocytosis (patients 1, 2, and 4, Table 2). Interestingly, in only two of the three cases, mast cell expression of CD30 was also found by immunohistochemistry. The two biopsies without detectable CD30 transcripts were also negative by immunohistochemistry (patients 3 and 5, Table 2). In conclusion, there was a good correlation between CD30 expression as detected by immunohistochemistry and CD30 mRNA expression in formalin-fixed and paraffinembedded biopsies. As expected, CD30 mRNA was also detected in extracts obtained from HMC-1 cells (not shown).

\section{Discussion}

Only a few characteristic markers, including $K I T^{\mathrm{D} 816 \mathrm{~V}} \mathrm{CD} 25$, and CD2, are expressed by neoplastic mast cells in systemic mastocytosis and thus serve as diagnostic criteria. ${ }^{20,22,24}$ As these 'diagnostic' markers are expressed by neoplastic mast cells in all systemic mastocytosis subtypes, they cannot be employed for differentiating between the variants of systemic mastocytosis in terms of grading of the disease. We here report that CD30, a member of the tumor necrosis factor receptor family, is expressed by neoplastic mast cells in most patients with highgrade systemic mastocytosis, whereas mast cells in the majority of patients with indolent systemic 

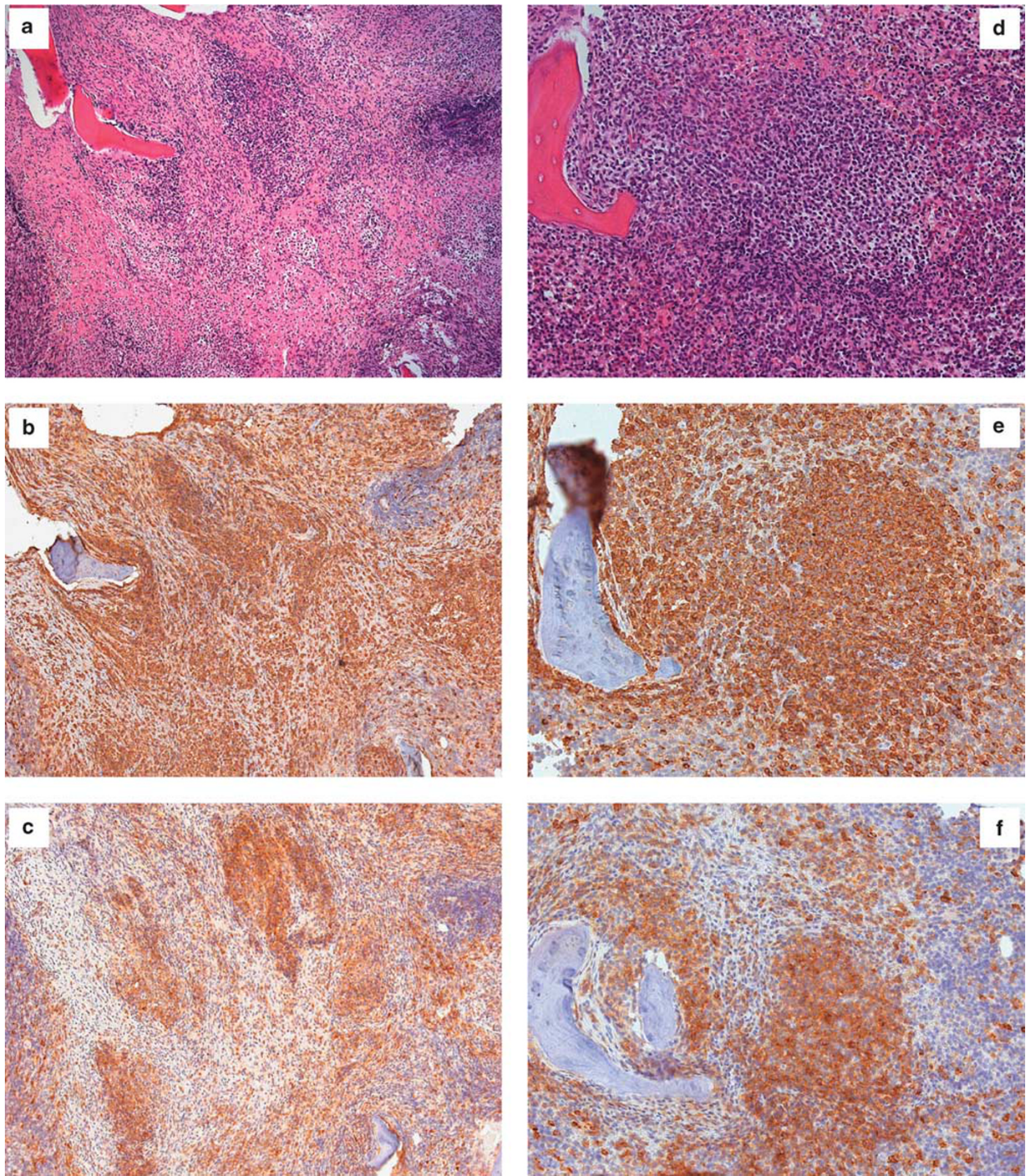

Figure 2 Strong expression of CD30 in advanced systemic mastocytosis. Bone marrow sections in a patient with mast cell leukemia. An overview showing diffuse mast cell infiltrates is given in (a, H\&E), (b, tryptase), and (c, CD30), while a more compact mast cell infiltrate in different region of the marrow is shown in (d, H\&E), (e, tryptase), and (f, CD30). Notably, clearly $>50 \%$ of mast cells show a strong expression of CD30, corresponding to stain pattern 'strongly positive' $(++)$.

mastocytosis are CD30-negative. Thus, CD30 may serve as a potential grading marker in systemic mastocytosis.

The finding that CD30 is a marker of neoplastic mast cells in high-grade systemic mastocytosis was unexpected because CD30 is otherwise expressed only in a limited number of neoplastic states. Therefore, further investigations were undertaken to confirm this finding by mRNA analysis. In line with the immunohistochemical findings, CD30 

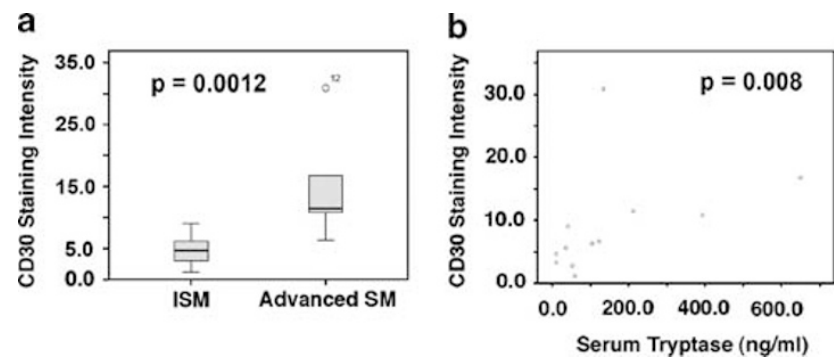

Figure 3 Quantification of CD30 expression in neoplastic mast cells in systemic mastocytosis. (a) TissueFAXS analysis of expression of CD30 in bone marrow mast cell infiltrates in patients with indolent systemic mastocytosis $(n=7$; left panel) and advanced systemic mastocytosis $(n=5$; smouldering systemic mastocytosis, $n=2$; aggressive systemic mastocytosis, $n=2$, aggressive systemic mastocytosis $\rightarrow$ mast cell leukemia; right panel). The levels of CD30 in compact mast cell infiltrates are significantly higher in advanced systemic mastocytosis than in indolent systemic mastocytosis $(P=0.012)$. (b) Significant $(P=0.008)$ correlation between expression of CD30 (by TissueFAXS) and serum tryptase levels in these patients $(R=0.72)$.

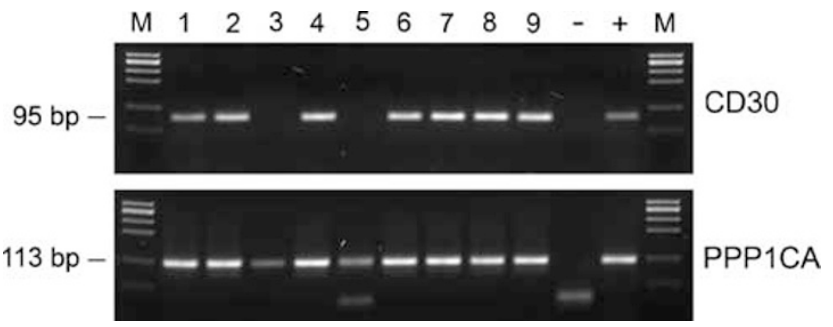

Figure 4 Detection of CD30 mRNA in systemic mastocytosis. CD30 transcripts were detected $3 / 5$ patients (lines 1,2 , and 4) with indolent forms of systemic mastocytosis (lines 1-5) and in 4/ 4 patients with aggressive systemic mastocytosis (lines 5-9). Structural integrity of extracted mRNA was verified by amplification of a 113-bp fragment of the alpha catalytic subunit of protein phosphatase 1 (PPP1CA). Messenger RNA from a case of Hodgkin lymphoma served as the positive control ' + '.

mRNA was clearly detectable in all investigated patients with CD30-positive immunohistochemistry, but was not detectable in normal/reactive bone marrow and non-mastocytic hematopoietic neoplasms. In this regard, it is noteworthy that in almost all patients with indolent systemic mastocytosis, a small population of CD30-positive cells, presumably mast cells, could be detected, even when the majority of CD25-positive neoplastic mast cells were CD30-negative. Interestingly, no CD30 transcripts were found in a case of unclassifiable myeloproliferative neoplasm and eosinophilia characterized by an increase in CD25-positive mast cells with atypical spindle-shaped morphology. Notably this case was wild-type at KIT codon 816.

The expression of CD30 in normal/reactive tissues is restricted to a few cell types. In fact, CD30 is only detectable in a small subset of lymphocytes, most probably proliferating T and B blasts. Among T cells, CD30 is considered to be expressed preferentially by helper $\mathrm{T}$ cells, especially Th2 cells. ${ }^{30,31,33,39,40}$ In neoplastic states, CD30 is known to be expressed by transformed cells in Hodgkin lymphoma (Hodgkin and Reed-Sternberg cells), anaplastic large cell lymphoma, and embryonal carcinoma. By contrast, the CD30 ligand (CD30L/CD153) is detectable in a variety of cell types, including $\mathrm{T}$ cells, granulocytes, monocytes/macrophages, and a proportion of bone marrow precursor cells of various lineages. ${ }^{41-43}$ The CD30 ligand is also expressed by Hodgkin and Reed-Sternberg cells, suggesting homotypic interactions and, possibly, autocrine growth regulation. It has recently been shown that mast cells express functional CD30L/CD153 and are the predominant CD30L-positive cells in Hodgkin lymphoma. ${ }^{44}$ In addition, functional CD30L has also been demonstrated in almost all mast cells of the HMC-1 mast cell leukemia cell line. ${ }^{44}$ Thus, the demonstration of the consistent expression of CD30 in the majority of neoplastic mast cells in aggressive variants of systemic mastocytosis may argue for possible interactions between CD30 and its ligand, CD153, in neoplastic mast cells. One possibility could be that CD30-CD153 interactions are involved in autocrine growth regulation. Such autocrine interactions via CD30 and its ligand have also been described in Hodgkin lymphoma. ${ }^{45,46}$ Whether CD30 signaling in neoplastic mast cells, like in anaplastic large cell lymphoma cells, triggers NF- $\kappa \mathrm{B}$-mediated increased survival needs to be addressed in further functional studies. ${ }^{47}$

The immunohistochemical and molecular demonstration of expression of CD30 by mast cells predominantly in the aggressive variants of mastocytosis may have important consequences for patients with this disease in several respects. First, CD30 can now be regarded as a potential grading marker in systemic mastocytosis that may be useful in screening for advanced disease. In addition, it may be employed to estimate the risk of progression of systemic mastocytosis in future studies. However, it should be noted that CD30 expression was also found in some patients in whom the clinical course had remained stable and, vice versa, a few patients showed rapid progression although their mast cells were clearly CD30-negative. Thus, CD30 expression by the mast cells in systemic mastocytosis is not invariably linked to an adverse prognosis. There are also other interesting aspects and unresolved questions concerning CD30 in systemic mastocytosis. For example, the functional role of CD30 and its ligand in systemic mastocytosis remains speculative. In previous studies, soluble CD30 was detected in the culture supernatant of CD30-positive tumor cell lines and in the sera of patients with CD30-positive Hodgkin lymphoma and anaplastic large cell lymphoma. ${ }^{4-50}$ In these patients, soluble CD30 levels were found to indicate a poor outcome. Whether sCD30 can be employed as a diagnostic or prognostic serum marker in patients with mastocytosis remains to be determined. It is also not known whether CD30 and the CD30 ligand have a role in the growth or survival of neoplastic mast cells. 
Another interesting aspect is that several CD30targeted therapeutic strategies have been developed, as reviewed by Hirsch et al. ${ }^{51}$ One of these molecules, chimeric anti-CD30 monoclonal antibody, has already demonstrated potent antitumor activity for both Hodgkin lymphoma and anaplastic large cell lymphoma in a preclinical phase II study. ${ }^{52}$ Whether CD30 can also serve as a potential target in advanced systemic mastocytosis remains unknown. The advantage of such therapy would be that expression of CD30 is limited to neoplastic cells and a few normal lymphocytes, leaving most normal tissues and stem cells unaffected.

In conclusion, the increased expression of CD30 in mast cells of the aggressive subtypes of systemic mastocytosis predicts an important role for this protein in the pathogenesis of the disease. In addition, CD30 may serve as an essential biomarker indicative of aggressive disease variants in systemic mastocytosis. Moreover, CD30 expression in mast cells in mastocytosis may be of value for disease monitoring and prognostication. Finally, it may be reasonable to evaluate CD30 as a potential target in systemic mastocytosis in future studies.

\section{Acknowledgements}

We are grateful to Dr Margaret Ruck for editing the language of the article. This study was supported by Fonds zur Förderung der Wissenschaftlichen Forschung in Österreich, Grants \#P21173-B13 and \#SFB-F01820.

\section{Disclosure/conflict of interest}

The authors declare no conflict of interest.

\section{References}

1 Lennert K, Parwaresch MR. Mast cells and mast cell neoplasia: a review. Histopathology 1979;3:349-365.

2 Metcalfe DD. Classification and diagnosis of mastocytosis: current status. J Invest Dermatol 1991;96: 2S-4S; discussion 4S, 60S-65S.

3 Valent P. Biology, classification and treatment of human mastocytosis. Wien Klin Wochenschr 1996;108: 385-397.

4 Valent P, Horny HP, Escribano L, et al. Diagnostic criteria and classification of mastocytosis: a consensus proposal. Leuk Res 2001;25:603-625.

5 Akin C, Metcalfe DD. Systemic mastocytosis. Annu Rev Med 2004;55:419-432.

6 Valent PHH-P, Li CY, Longley JB, et al. Mastocytosis (mast cell disease). In: Jaffe ES HN, Stein H, Vardiman JW (eds). WHO Classification of Tumours. Tumours of Haematopoietic and Lymphoid Tissues IARC Press: Lyon, France, 2001, pp 291-302.

7 Horny H-P, Bennett JM, Bain BJ, et al. Mastocytosis (mast cell disease). In: Swerdlow SH CE, Harris NL, Jaffe ES, Pileri SA, Stein H, Thiele J, Vardiman JW (eds). WHO Classification of Tumours of Haematopoietic and Lymphoid Tissues. IARC Press: Geneva, Switzerland, 2008, pp 54-63.

8 Valent P, Akin C, Sperr WR, et al. Diagnosis and treatment of systemic mastocytosis: state of the art. Br J Haematol 2003;122:695-717.

9 Escribano L, Alvarez-Twose I, Sanchez-Munoz L, et al. Prognosis in adult indolent systemic mastocytosis: a long-term study of the Spanish network on mastocytosis in a series of 145 patients. J Allergy Clin Immunol 2009;124:514-521.

$10 \mathrm{Lim}$ KH, Tefferi A, Lasho TL, et al. Systemic mastocytosis in 342 consecutive adults: survival studies and prognostic factors. Blood 2009;113: 5727-5736.

11 Valent P, Akin C, Escribano L, et al. Standards and standardization in mastocytosis: consensus statements on diagnostics, treatment recommendations and response criteria. Eur J Clin Invest 2007;37:435-453.

12 Valent P, Ghannadan M, Akin C, et al. On the way to targeted therapy of mast cell neoplasms: identification of molecular targets in neoplastic mast cells and evaluation of arising treatment concepts. Eur J Clin Invest 2004;34(Suppl 2):41-52.

13 Tefferi A, Pardanani A. Clinical, genetic, and therapeutic insights into systemic mast cell disease. Curr Opin Hematol 2004;11:58-64.

14 Pardanani A, Akin C, Valent P. Pathogenesis, clinical features, and treatment advances in mastocytosis. Best Pract Res Clin Haematol 2006;19:595-615.

15 Nagata H, Worobec AS, Oh CK, et al. Identification of a point mutation in the catalytic domain of the protooncogene c-kit in peripheral blood mononuclear cells of patients who have mastocytosis with an associated hematologic disorder. Proc Natl Acad Sci USA 1995; 92:10560-10564.

16 Longley BJ, Tyrrell L, Lu SZ, et al. Somatic c-KIT activating mutation in urticaria pigmentosa and aggressive mastocytosis: establishment of clonality in a human mast cell neoplasm. Nat Genet 1996;12:312-314.

17 Longley Jr BJ, Metcalfe DD, Tharp M, et al. Activating and dominant inactivating c-KIT catalytic domain mutations in distinct clinical forms of human mastocytosis. Proc Natl Acad Sci USA 1999;96: 1609-1614.

18 Fritsche-Polanz R, Jordan JH, Feix A, et al. Mutation analysis of C-KIT in patients with myelodysplastic syndromes without mastocytosis and cases of systemic mastocytosis. Br J Haematol 2001;113:357-364.

19 Feger F, Ribadeau Dumas A, Leriche L, et al. Kit and c-kit mutations in mastocytosis: a short overview with special reference to novel molecular and diagnostic concepts. Int Arch Allergy Immunol 2002;127: 110-114.

20 Garcia-Montero AC, Jara-Acevedo M, Teodosio C, et al. KIT mutation in mast cells and other bone marrow hematopoietic cell lineages in systemic mast cell disorders: a prospective study of the Spanish network on mastocytosis (REMA) in a series of 113 patients. Blood 2006;108:2366-2372.

21 Furitsu T, Tsujimura T, Tono T, et al. Identification of mutations in the coding sequence of the protooncogene c-kit in a human mast cell leukemia cell line causing ligand-independent activation of c-kit product. J Clin Invest 1993;92:1736-1744.

22 Escribano L, Orfao A, Villarrubia J, et al. Immunophenotypic characterization of human bone marrow mast 
cells. A flow cytometric study of normal and pathological bone marrow samples. Anal Cell Pathol 1998;16:151-159.

23 Escribano L, Diaz-Agustin B, Bellas C, et al. Utility of flow cytometric analysis of mast cells in the diagnosis and classification of adult mastocytosis. Leuk Res 2001;25:563-570.

24 Sotlar K, Horny HP, Simonitsch I, et al. CD25 indicates the neoplastic phenotype of mast cells: a novel immunohistochemical marker for the diagnosis of systemic mastocytosis (SM) in routinely processed bone marrow biopsy specimens. Am J Surg Pathol 2004;28:1319-1325.

25 Horny HP, Sillaber C, Menke D, et al. Diagnostic value of immunostaining for tryptase in patients with mastocytosis. Am J Surg Pathol 1998;22:1132-1140.

26 Jordan JH, Fritsche-Polanz R, Sperr WR, et al. A case of 'smouldering' mastocytosis with high mast cell burden, monoclonal myeloid cells, and C-KIT mutation Asp-816-Val. Leuk Res 2001;25:627-634.

27 Baumgartner C, Cerny-Reiterer S, Sonneck K, et al. Expression of activated STAT5 in neoplastic mast cells in systemic mastocytosis: subcellular distribution and role of the transforming oncoprotein KIT D816V. Am J Pathol 2009;175:2416-2429.

28 Teodosio C, Garcia-Montero AC, Jara-Acevedo M, et al. Mast cells from different molecular and prognostic subtypes of systemic mastocytosis display distinct immunophenotypes. J Allergy Clin Immunol 2010;125: 719-726, 726.e1-726.e4.

29 Schwab U, Stein H, Gerdes J, et al. Production of a monoclonal antibody specific for Hodgkin and Sternberg-Reed cells of Hodgkin's disease and a subset of normal lymphoid cells. Nature 1982;299:65-67.

30 Stein H, Mason DY, Gerdes J, et al. The expression of the Hodgkin's disease associated antigen Ki-1 in reactive and neoplastic lymphoid tissue: evidence that Reed-Sternberg cells and histiocytic malignancies are derived from activated lymphoid cells. Blood 1985;66:848-858.

31 Chiarle R, Podda A, Prolla G, et al. CD30 in normal and neoplastic cells. Clin Immunol 1999;90:157-164.

32 Pileri SA, Ascani S, Cox MC, et al. Myeloid sarcoma: clinico-pathologic, phenotypic and cytogenetic analysis of 92 adult patients. Leukemia 2007;21: 340-350.

33 Segal GH, Kjeldsberg CR, Smith GP, et al. CD30 antigen expression in florid immunoblastic proliferations. A clinicopathologic study of 14 cases. Am J Clin Pathol 1994;102:292-298.

34 Hsu SM, Raine L, Fanger H. Use of avidin-biotinperoxidase complex (ABC) in immunoperoxidase techniques: a comparison between $\mathrm{ABC}$ and unlabeled antibody (PAP) procedures. J Histochem Cytochem 1981;29:577-580.

35 Steiner GE, Ecker RC, Kramer G, et al. Automated data acquisition by confocal laser scanning microscopy and image analysis of triple stained immunofluorescent leukocytes in tissue. J Immunol Methods 2000;237: 39-50.

36 Harir N, Boudot C, Friedbichler K, et al. Oncogenic kit controls neoplastic mast cell growth through a Stat5/PI3kinase signaling cascade. Blood 2008;112:2463-2473.
37 Sotlar K, Escribano L, Landt O, et al. One-step detection of c-kit point mutations using peptide nucleic acid-mediated polymerase chain reaction clamping and hybridization probes. Am J Pathol 2003;162:737-746.

38 Sotlar K, Colak S, Bache A, et al. Variable presence of $\mathrm{KIT}(\mathrm{D} 816 \mathrm{~V})$ in clonal haematological non-mast cell lineage diseases associated with systemic mastocytosis (SM-AHNMD). J Pathol 2009;220:586-595.

39 Bengtsson A, Johansson C, Linder MT, et al. Not only Th2 cells but also Th1 and Th0 cells express CD30 after activation. J Leukoc Biol 1995;58:683-689.

40 Pallesen G. The diagnostic significance of the CD30 (Ki-1) antigen. Histopathology 1990;16:409-413.

41 Smith CA, Gruss HJ, Davis T, et al. CD30 antigen, a marker for Hodgkin's lymphoma, is a receptor whose ligand defines an emerging family of cytokines with homology to TNF. Cell 1993;73:1349-1360.

42 Armitage RJ. Tumor necrosis factor receptor superfamily members and their ligands. Curr Opin Immunol 1994;6:407-413.

43 Gattei V, Degan M, Gloghini A, et al. CD30 ligand is frequently expressed in human hematopoietic malignancies of myeloid and lymphoid origin. Blood 1997;89:2048-2059.

44 Molin D, Fischer M, Xiang Z, et al. Mast cells express functional CD30 ligand and are the predominant CD30L-positive cells in Hodgkin's disease. $\mathrm{Br} \mathrm{J}$ Haematol 2001;114:616-623.

45 Gruss HJ, Pinto A, Gloghini A, et al. CD30 ligand expression in nonmalignant and Hodgkin's diseaseinvolved lymphoid tissues. Am J Pathol 1996;149: 469-481.

46 Hsu PL, Hsu SM. Autocrine growth regulation of CD30 ligand in CD30-expressing Reed-Sternberg cells: distinction between Hodgkin's disease and anaplastic large cell lymphoma. Lab Invest 2000;80:1111-1119.

47 Hirsch B, Hummel M, Bentink S, et al. CD30-induced signaling is absent in Hodgkin's cells but present in anaplastic large cell lymphoma cells. Am J Pathol 2008;172:510-520.

48 Josimovic-Alasevic O, Durkop $\mathrm{H}$, Schwarting $\mathrm{R}$, et al. $\mathrm{Ki}-1$ (CD30) antigen is released by Ki-1-positive tumor cells in vitro and in vivo. I. Partial characterization of soluble Ki-1 antigen and detection of the antigen in cell culture supernatants and in serum by an enzymelinked immunosorbent assay. Eur J Immunol 1989;19:157-162.

49 Nadali G, Tavecchia L, Zanolin E, et al. Serum level of the soluble form of the CD30molecule identifies patients with Hodgkin's disease at high risk of unfavorable outcome. Blood 1998;91:3011-3016.

50 Zinzani PL, Pileri S, Bendandi M, et al. Clinical implications of serum levels of soluble CD30 in 70 adult anaplastic large-cell lymphoma patients. J Clin Oncol 1998;16:1532-1537.

51 Hirsch B, Brauer J, Fischdick M, et al. Anti-CD30 human IL-2 fusion proteins display strong and specific cytotoxicity in vivo. Curr Drug Targets 2009;10:110-117.

52 Forero-Torres A, Leonard JP, Younes A, et al. A Phase II study of SGN-30 (anti-CD30mAb) in Hodgkin lymphoma or systemic anaplastic large cell lymphoma. Br J Haematol 2009;146:171-179. 